\title{
CD248(TEM1/CD164L1/Endosialin): A new molecular target for anti-angiogenic therapy in Pancreatic ductal adenocarcinoma
}

\section{Huan Zhang ( $2962845218 @ q q . c o m$ ) \\ Yangzhou University https://orcid.org/0000-0002-2289-7707}

\section{Zhujiang Dai}

Yangzhou University

\section{Yiqun Liao}

Northern Jiangsu People's Hospital

\section{Cheng Yan}

Northern Jiangsu People's Hospital

\section{Bin Zhao}

Northern Jiangsu People's Hospital

Tian Liu

Yangzhou University

Jie Zhang

Yangzhou University

Juan Xing

Yangzhou University

Wenjie Zhang

Yangzhou University

Jingqiu Zhang

Northern Jiangsu People's Hospital

\section{Daorong Wang}

Northern Jiangsu People's Hospital

\section{Dong Tang}

Northern Jiangsu People's Hospital

Primary research

Keywords: CD248, PDCA, anti-angiogenic therapy, molecular targets

Posted Date: March 18th, 2021

DOl: https://doi.org/10.21203/rs.3.rs-217476/v1 
License: (c) (i) This work is licensed under a Creative Commons Attribution 4.0 International License. Read Full License 


\section{Abstract}

Background: Pancreatic ductal adenocarcinoma (PDCA) is one of the malignant tumors with the worst prognosis with a 5 -year survival rate of $<1 \%$, which is known as the "king of cancers". At present, there is a lack of effective early diagnosis and treatment plan for pancreatic cancer. Therefore, there is an urgent need to understand the molecular mechanisms of pancreatic cancer to generate innovative approaches for the development of effective early diagnosis and treatment strategies.

Methods: In this study, we performed single gene pan-cancer analysis, gene co-expression analysis and gene regulatory correlation analysis to understand the molecular mechanism of CD248 in pancreatic cancer using bioinformatics tools. Additionally, we provided potential molecular targets for pancreatic cancer treatment by constructing the IncRNA-miRNA-gene network axis.

Results: The results showed that CD248 is differentially expressed in normal and tumor tissues, and abnormally high expression predicts poor prognosis, is a proto-oncogene in pancreatic cancer. Besides, CD248 is associated with angiogenesis of tumors. We obtained three new IncRNA-miRNA-gene network axes, namely AC008040.1-hsa-miR-200c-3p-CD248 axis, AC055822.1-hsa-miR-200c-3p-CD248 axis, RRN3P2-hsa-miR-200c-3p-CD248 axis that provide promising molecular targets for anti-angiogenic therapy and diagnostic biomarkers for pancreatic cancer.

Conclusion: In conclusion, this study shows that over-expression of CD248 (TEM1/CD164L1/Endosialin) is always present in breast cancer and predicts a poor prognosis, associated with tumor angiogenesis, suggesting it as an attractive therapeutic target for pancreatic cancer.

\section{Background}

Pancreatic cancer is a highly lethal malignancy that progresses rapidly. According to Cancer statistics 2021 estimates, pancreatic cancer is the fourth leading cause of cancer death in men and women in the United States, approximately 60,430 new cases and 48,220 deaths, with both incidence and mortality on the rise[1]. Early symptoms of pancreatic cancer that are insidious and atypical often leading to delayed diagnosis, and by the time it is diagnosed, it is almost close to advanced stage with rapid progression and high mortality[2]. At present, the effective treatment choices for pancreatic cancer are limited, and surgical resection is the only chance for cure. Adjuvant chemotherapy can improve the long-term prognosis of these patients, but surgical resection is only applicable to some patients and there are still risks of surgical complications and cancer metastasis, resulting in a low cure rate of pancreatic cancer[3]. The pathogenesis of pancreatic cancer, being the function and interaction of multiple genes at multiple steps, is extremely complex. Therefore, there is an urgent need to understand the molecular mechanisms of pancreatic cancer, which may lead innovative approaches for the development of effective early diagnosis and treatment strategies.

Dysregulated gene expression is a major feature of cancer. RNA genes have a significant impact on tumorigenesis, growth and progression[4-19]. RNA is divided into coding RNA (mRNA) and non-coding 
RNA (ncRNA) that includes miRNA, IncRNA, pseudogene, circRNA, etc[9]. In the nucleus, mRNA is transcribed, processed, and transported to the cytoplasm, where it is translated by tRNA in the ribosome thereby synthesizing proteins[7, 9] (Fig. 1). The ability of non-coding RNA genes that occupy multiple nodes in the cancer network is expressed through the context-dependent function of individual gene products and the production of different products from a single gene locus, where IncRNAs and miRNAs can regulate mRNA genes through competitive binding and interact to together regulating the onset and development of tumor tissue[20]. In the cytoplasm, miRNAs act as specific components of the ribonucleoprotein silencing complex and bind to target mRNAs to negatively regulate gene expression and protein translation by accelerating the demethylation and degradation of target mRNAs[9, 21-24]. IncRNAs, RNAs with more than 200 nucleotides that do not encode proteins, act as miRNA "sponges" in the cytoplasm to regulate mRNA expression which means preventing miRNAs from binding to mRNAs to protect them from degradation. Based on the characteristics of the above RNA gene regulatory network, we can know that the expression of mRNA can be down-regulated by inhibiting the expression of IncRNA or up-regulating the expression of miRNA. As thus, we have explored the IncRNA-miRNA-gene network axis of CD248 in pancreatic cancer to obtain a potential molecular targeting therapeutic pathway.

CD248 is a protein-coding gene that localized on the long arm of human chromosome 11 with an open reading frame of $2274 \mathrm{bp}$ and encodes a 757 amino acid type I transmembrane protein, also known as endothelin[25, 26]. In our study, CD248 was found to be expressed at obviously different levels in normal tissues versus in pancreatic cancer tissues, and high CD248 expression was associated with poor overall survival and progression-free survival in pancreatic cancer patients. In addition, CD248 has been suggested to be associated with tumor angiogenesis, which has been claimed as a potential target for anti-pancreatic cancer therapy. These results suggest that CD248 is a novel proto-oncogene. Therefore, we studied CD248 expression and data mutations in PDCA patients using bioinformatics research methods in The Cancer Genome Atlas (TCGA) and various public databases. Using multiple analytical approaches, we analyzed the genomic alterations and functional networks associated with CD248 in PDCA and constructed a IncRNA-miRNA-gene network associated with pancreatic cancer progression. Hence, our results may reveal new targets and strategies for pancreatic cancer diagnosis and treatment.

\section{Materials And Methods}

\section{Genetic information collection}

In this study, we used Cancersea, PubMed, Genecards, UniprotKB, OMIM and other online websites to search for information related to CD248. PubMed (https://pubmed.ncbi.nlm.nih.gov/) is a widely used in biomedical literature search engine[27]. Cancersea (http://biocc.hrbmu.edu.cn/CancerSEA) provides a user-friendly interface, used for comprehensive search, browse, visualization and download the tens of thousands of a single cancer cell function state activity profiles and the corresponding PCGs/IncRNAs expression profiles[28]. GeneCards \https://www.genecards.org/『is a comprehensive, authoritative compendium of annotative information about human genes,and provides users with a web-based deeplinked card[29, 30]. UniProtKB囚https://www.uniprot.org/囚provides users with a comprehensive, high- 
quality and freely accessible set of protein sequences annotated with functional information[31]. OMIM \http://omim.org冈provides interactive access to the knowledge repository, including genomic coordinate searches of the gene map, views of genetic heterogeneity of phenotypes in Phenotypic Series, and sideby-side comparisons of clinical synopses[32].

\section{Data mining from public databases}

Firstly, we searched SangerBox (http://sangerbox.com/Index), an online data analysis platform to study the differential expression of CD248 in tumor and normal tissues, which provides a fast way to download the TCGA database and builds an efficient and easy-to-use data mining tool for users. We next downloaded clinical data of PDCA patients, CD248 co-expressed genes from the TCGA database through the cBioPortal website (https://www.cbioportal.org/)[33]. cBioPortal simplifies molecular profiling data from cancer tissues and cell lines into easy-to-understand genetic, epigenetic, gene expression and proteomic events, providing a web resource for exploring, visualizing, and analyzing multidimensional cancer genomics data.

\section{Go and KEGG Pathway enrichment analysis}

In this study, a PPI network of co-expressed genes was constructed using the STRING database (http://string-db.org) with an interaction score of $>0.4$. Network analysis (https://www.networkanalyst.ca/NetworkAnalyst/home.xhtml) is a visual analysis platform that integrates gene expression analysis and meta-analysis[34-39]. Cytoscape (version 3.8.0) is an open bioinformatics software platform for visualizing molecular interaction networks[40]. First, we studied the genes co-expressed with CD248 in pancreatic cancer and the cancer genome using cBioPortal to obtain Spearman correlations $>0.7$ and $p<0.05$. Next, PPI networks were created using Network analysis or STRING and mapped using Cytoscape. Then, functional and pathway enrichment analysis was performed by STRING, including Gene Ontology (GO) biological processes and kyoto encyclopedia of genic and genomic pathway encyclopedia (KEGG pathway). Finally, the enriched data were visualized by SangerBox.

\section{Gene regulation analysis}

GraphPad Prism is an efficient and easy-to-use scientific graphing tool that combines scientific graphics, comprehensive curve fitting (non-linear regression), comprehensible statistics, and data organization. ENCORI (http://starbase.sysu.edu.cn/index.php) is a network platform that identifies over 1.1 million mRNA-ncRNA, 2.5 million miRNA-mRNA, 2.1 million RBP -RNAs and 1.5 million RNA-RNA interactions from a web-based platform[41]. Here, we used GraphPad Prism (version 9.0) software to analyze the relationship between miRNAs and CD248 in the TCGA database. ENCORI was used to analyze the relevance and prognostic impact of individual miRNA-associated IncRNAs in pancreatic cancer.

\section{Statistical analysis}


We used t-test in comparing the difference in CD248 expression in normal and tumor tissues $(\mathrm{p}<0.05)$. The effect of CD248 expression on PDCA prognosis was evaluated using Kaplan-Meier curves (95\% confidence interval $(\mathrm{Cl})$ not including $1, \mathrm{p}<0.05)$. In the analysis of co-expression with CD248 gene, the linear correlation between the two genes was measured using Spearman's correlation coefficient $(r>0.70$, $\mathrm{p}<0.05$ ). In addition, when we analyzed miRNA data, we performed using GraphPad Prism (version 9.0) software and measured the correlation between miRNA and CD248 expression by Pearson correlation coefficient $(r<0, p<0.05)$. $p<0.05$ was considered to be statistically significant.

\section{Results}

\section{CD248 is highly expressed in pancreatic cancer and results in a poor prognosis}

In this study, we first analyzed the transcript levels of CD248 gene in multiple tumor tissues through TCGA and GTEx datasets and observed the gene expression in 27 tissues (Fig. 2a). According to the data, the expression of CD248 was significantly different in several tumor tissues compared with normal tissues ( $\mathrm{p} \otimes 0.05$ ), among which, the expression of CD248 was significantly higher in pancreatic cancer than in normal tissues. Next, for the pancreatic cancer aspect, we combined the data with survival analysis of CD248 to obtain Kaplan-Meier curves (Fig. 2C). The results showed that the upregulation of CD248 leads to poor prognosis in PDCA. Therefore, CD248 can be considered as a proto-oncogene and a potential therapeutic target for PDCA, and CD248 expression can be used as a potential diagnostic indicator for PDCA.

\section{E334K and R41C mutations of CD248 in PDCA}

We then used cBioPortal to determine the type and frequency of CD248 mutations in PDCA based on sequencing data from patients in the TCGA database. We analyzed the mRNA transcripts and copynumber alterations of CD248 in 176 patients. The result shows that copy-number alterations include amplification, gain, diploid and shallow deletion, and diploid expression was the most abundant (Fig. 2d). In PDCA, the frequency of somatic mutations in CD248 was low at $1.1 \%$. The two known mutation types, both of which were missense mutations and both replicated as diploid, were the E334K and R41C mutations (Fig. 2b).

\section{PPI of CD248 in PDCA}

To identify the biological interaction network of CD248 in PDCA, we searched for co-expression target genes related to CD248 in pancreatic cancer through cBioPortal in the TCGA database. A total of 104 related genes (Spearman's Correlation $>0.7, p<0.05$ ) were selected to obtain the gene co-expression network for protein interaction analysis (Fig. 3).

\section{Enrichment analysis: CD248 was related to tumor angiogenesis}

Then, in order to analyze the biological classification of co-expressed genes, we used String, Cytoscape and other tools to perform GO function and KEGG pathway enrichment analysis. The concentration of GO 
biological process (BP) is mainly related to regulation of biological process, multicellular organismal process, developmental process, anatomical structure development, multicellular organism development, system development, positive regulation of biological process, etc. (Fig. 4a). The enriched GO molecular function (MF) items are mainly associated with ion binding, protein binding, metal ion binding, proteincontaining complex binding, signaling receptor binding, structural molecule activity, calcium ion binding, extracellular matrix structural constituent and integrin binding and so on are related to each other (Fig. 4b). The enriched GO celluar component (CC) items are mainly related to extracellular region, intracellular organelle lumen, endomembrane system, extracellular matrix, endoplasmic reticulum, extracellular space, endoplasmic reticulum lumen and supramolecular polymer, etc. (Fig. 4c). The enrichment of KEGG pathways includes protein digestion and absorption, focal adhesion, human papillomavirus infection, PI3K-Akt signaling pathway, ECM-receptor interaction, relaxin signaling pathway, AGE-RAGE signaling pathway in Diabetic complications, microRNAs in cancer, proteoglycans in cancer, etc. (Fig. 4d). All in all, these data suggest that CD248 is involved in many fundamental life processes and may play roles in regulating signal transduction, protein binding and vascular development in tumor.

\section{LncRNA-miRNA-gene network axes of CD248 in PDCA}

Finally, to further explore the target of CD248 in PDCA, we analyzed the miRNAs negatively associated with CD248 in the TCGA database and the IncRNAs negatively associated with the corresponding miRNAs. First and foremost, we screened the following 70 miRNAs, which were negatively correlated with the expression of CD248 in pancreatic cancer, by GraphPad Prism analysis (Table 1). Then, we used ENCORI and SangerBox to analyze the differences in expression of these 70 miRNAs in normal tissues and pancreatic cancer and their relationship with pancreatic cancer prognosis. We obtained one miRNA (hsa-miR-200c-3p) with differential expression in normal tissues and in tumor tissues and its high expression predicted a better prognosis (Fig. 5a-c). We then used ENCORI to analyze the IncRNAs associated with miRNAs and obtained 15 IncRNAs (AC008040.1, AC015813.6, AC025569.1, AC027279.4, AC055822.1, AL049796.1, AL353796.1, AP001486.2, HELLPAR, LINC01140, LINC01303, MSC-AS1, OIP5AS1, RRN3P2, ZNF433-AS1) were negatively correlated with hsa-miR-200c-3p, but only three of the above 15 IncRNAs (AC008040.1, AC055822.1, RRN3P2) were differentially expressed in normal tissues versus in pancreatic cancer tissues (Fig. 5d-i). Therefore, we obtained three new IncRNA-miRNA-gene network axes, namely AC008040.1-hsa-miR-200c-3p-CD248 axis, AC055822.1-hsa-miR-200c-3p-CD248 axis and RRN3P2-hsa-miR-200c-3p- CD248 axis, are potential pathways and potential therapeutic targets for regulating pancreatic cancer progression.

\section{Table 1 Summary of 70 miRNAs negatively correlated with CD248. (The table shows the ID of miRNA.)}




\begin{tabular}{|c|c|c|c|c|}
\hline miRNA & $\mathbf{r}$ & 95\% confidence interval & P value & $P$ value summary \\
\hline MIMAT0000242 & -0.1349 & -0.2148 to -0.05311 & 0.0013 & $* *$ \\
\hline MIMAT0005914 & -0.1342 & -0.2142 to -0.05244 & 0.0014 & $* *$ \\
\hline MIMAT0022473 & -0.1299 & -0.2100 to -0.04810 & 0.0019 & $* *$ \\
\hline MIMAT0004598 & -0.1294 & -0.2095 to -0.04757 & 0.002 & $* *$ \\
\hline MIMAT0004558 & -0.1275 & -0.2077 to -0.04563 & 0.0024 & $* *$ \\
\hline MIMAT0022496 & -0.1265 & -0.2067 to -0.04464 & 0.0025 & $* *$ \\
\hline MIMAT0006789 & -0.1243 & -0.2046 to -0.04241 & 0.003 & $* *$ \\
\hline MIMAT0003218 & -0.1229 & -0.2032 to -0.04094 & 0.0034 & $* *$ \\
\hline MIMAT0018072 & -0.1196 & -0.1999 to -0.03759 & 0.0044 & $* *$ \\
\hline MIMAT0007399 & -0.1163 & -0.1968 to -0.03432 & 0.0055 & $* *$ \\
\hline MIMAT0025477 & -0.1152 & -0.1957 to -0.03322 & 0.006 & $* *$ \\
\hline MIMAT0018353 & -0.1144 & -0.1949 to -0.03239 & 0.0064 & $* *$ \\
\hline MIMAT0031893 & -0.113 & -0.1935 to -0.03094 & 0.0071 & $* *$ \\
\hline MIMAT0011777 & -0.1107 & -0.1913 to -0.02863 & 0.0083 & $* *$ \\
\hline MIMAT0027368 & -0.1105 & -0.1911 to -0.02846 & 0.0084 & $* *$ \\
\hline MIMAT0004605 & -0.1098 & -0.1904 to -0.02772 & 0.0089 & $* *$ \\
\hline MIMAT0019778 & -0.1092 & -0.1898 to -0.02707 & 0.0093 & $* *$ \\
\hline MIMAT0002878 & -0.1087 & -0.1894 to -0.02662 & 0.0096 & $* *$ \\
\hline MIMAT0004682 & -0.1073 & -0.1880 to -0.02521 & 0.0105 & $*$ \\
\hline MIMAT0030419 & -0.1068 & -0.1875 to -0.02472 & 0.0109 & $*$ \\
\hline MIMAT0003322 & -0.1064 & -0.1871 to -0.02430 & 0.0112 & * \\
\hline MIMAT0025470 & -0.106 & -0.1868 to -0.02391 & 0.0115 & $*$ \\
\hline MIMAT0004657 & -0.1031 & -0.1838 to -0.02090 & 0.0141 & $*$ \\
\hline MIMAT0009451 & -0.1027 & -0.1835 to -0.02050 & 0.0145 & * \\
\hline MIMAT0019747 & -0.1019 & -0.1827 to -0.01972 & 0.0152 & * \\
\hline MIMAT0022482 & -0.09947 & -0.1803 to -0.01726 & 0.0178 & $*$ \\
\hline
\end{tabular}




\begin{tabular}{|c|c|c|c|c|}
\hline MIMAT0017992 & -0.09933 & -0.1802 to -0.01712 & 0.018 & $*$ \\
\hline MIMAT0002875 & -0.09887 & -0.1798 to -0.01667 & 0.0185 & $*$ \\
\hline MIMAT0000255 & -0.09789 & -0.1788 to -0.01567 & 0.0197 & $*$ \\
\hline MIMAT0004585 & -0.09775 & -0.1787 to -0.01554 & 0.0199 & $*$ \\
\hline MIMAT0019725 & -0.09627 & -0.1772 to -0.01403 & 0.0219 & $*$ \\
\hline MIMAT0018004 & -0.09554 & -0.1765 to -0.01330 & 0.0229 & $*$ \\
\hline MIMAT0004592 & -0.0948 & -0.1758 to -0.01256 & 0.024 & $*$ \\
\hline MIMAT0004702 & -0.09468 & -0.1757 to -0.01243 & 0.0242 & $*$ \\
\hline MIMAT0017996 & -0.09411 & -0.1751 to -0.01186 & 0.025 & $*$ \\
\hline MIMAT0005924 & -0.09382 & -0.1748 to -0.01157 & 0.0255 & $*$ \\
\hline MIMAT0002881 & -0.09343 & -0.1744 to -0.01118 & 0.0261 & $*$ \\
\hline MIMAT0027396 & -0.09322 & -0.1742 to -0.01096 & 0.0264 & $*$ \\
\hline MIMAT0002807 & -0.09307 & -0.1741 to -0.01081 & 0.0267 & $*$ \\
\hline MIMAT0022500 & -0.09246 & -0.1735 to -0.01020 & 0.0277 & $*$ \\
\hline MIMAT0004611 & -0.09176 & -0.1728 to -0.009492 & 0.0289 & $*$ \\
\hline MIMAT0019707 & -0.09152 & -0.1726 to -0.009242 & 0.0293 & $*$ \\
\hline MIMAT0022966 & -0.09063 & -0.1717 to -0.008349 & 0.0309 & $*$ \\
\hline MIMAT0002883 & -0.09021 & -0.1713 to -0.007929 & 0.0317 & $*$ \\
\hline MIMAT0027394 & -0.09013 & -0.1712 to -0.007843 & 0.0319 & $*$ \\
\hline MIMAT0014987 & -0.0894 & -0.1705 to -0.007110 & 0.0333 & $*$ \\
\hline MIMAT0005919 & -0.08843 & -0.1695 to -0.006137 & 0.0353 & $*$ \\
\hline MIMAT0002879 & -0.08824 & -0.1694 to -0.005944 & 0.0357 & $*$ \\
\hline MIMAT0003284 & -0.08785 & -0.1690 to -0.005551 & 0.0365 & $*$ \\
\hline MIMAT0000617 & -0.08737 & -0.1685 to -0.005062 & 0.0375 & $*$ \\
\hline MIMAT0002880 & -0.0873 & -0.1684 to -0.004990 & 0.0377 & $*$ \\
\hline MIMAT0018358 & -0.08673 & -0.1679 to -0.004416 & 0.039 & $*$ \\
\hline MIMAT0003296 & -0.08578 & -0.1669 to -0.003462 & 0.0412 & $*$ \\
\hline
\end{tabular}




\begin{tabular}{llllll}
\hline MIMAT0019763 & -0.08563 & -0.1668 to -0.003311 & 0.0415 & $*$ \\
\hline MIMAT0019210 & -0.08561 & -0.1668 to -0.003292 & 0.0416 & $*$ \\
\hline MIMAT0003265 & -0.08455 & -0.1657 to -0.002220 & 0.0442 & $*$ \\
\hline MIMAT0002877 & -0.08422 & -0.1654 to -0.001896 & 0.045 & $*$ \\
\hline MIMAT0019754 & -0.08421 & -0.1654 to -0.001882 & 0.045 & $*$ \\
\hline MIMAT0000245 & -0.08419 & -0.1654 to -0.001856 & 0.0451 & $*$ \\
\hline MIMAT0003327 & -0.08329 & -0.1645 to -0.0009492 & 0.0475 & $*$ \\
\hline MIMAT0000264 & -0.2457 & -0.3215 to -0.1667 & $<0.0001$ & $* * * *$ \\
\hline MIMAT0022975 & -0.2337 & -0.3101 to -0.1543 & $<0.0001$ & $* * * *$ \\
\hline MIMAT0003294 & -0.1995 & -0.2773 to -0.1191 & $<0.0001$ & $* * * *$ \\
\hline MIMAT0031890 & -0.1879 & -0.2661 to -0.1072 & $<0.0001$ & $* * * *$ \\
\hline MIMAT0027361 & -0.1814 & -0.2598 to -0.1005 & $<0.0001$ & $* * * *$ \\
\hline MIMAT0018349 & -0.1792 & -0.2577 to -0.09831 & $<0.0001$ & $* * * *$ \\
\hline MIMAT0028222 & -0.1758 & -0.2545 to -0.09483 & $<0.0001$ & $* * * *$ \\
\hline MIMAT0005920 & -0.172 & -0.2508 to -0.09094 & $<0.0001$ & $* * * *$ \\
\hline MIMAT0027362 & -0.1638 & -0.2428 to -0.08252 & $<0.0001$ & $* * * *$ \\
\hline
\end{tabular}

$*, \mathrm{P}<0.05 ; * *, \mathrm{p}<0.01 ; * * *, \mathrm{p}<0.001 ; * * * *, \mathrm{p}<0.0001$

\section{Discussion}

Pancreatic cancer is one of the most common malignancies worldwide, with no obvious clinical signs and symptoms in the early stages and rapid progression in the late stages, leading to its extremely poor prognosis. A better understanding of the mechanisms of pancreatic cancer development and progression can facilitate the formation of effective early diagnosis and treatment options.

In our study, based on comprehensive bioinformatics analysis, it was found that CD248 was not only significantly increased in pancreatic cancer samples, but also its upregulation was associated with poor prognosis in pancreatic cancer patients and was determined to be related to the progression of pancreatic cancer. By enriching the TCGA database for PPI networks and functions and pathways that are highly correlated with CD248, we learned that CD248 may be associated with tumor angiogenesis and miRNA regulation. Initially, the study by St Croix et al. suggested that CD248 was expressed in vascular endothelial cells of malignant tumors, and they identified transcripts of PEMs and TEMs by sequence 
analysis of gene expression (SAGE), and RT-PCR and in situ hybridization analysis showed that TEM1 (CD248) expression was restricted to tumor endothelial tissues and metastatic lesions and was undetectable in normal tissues[42]. It was thought that CD248 was expressed in tumor vascular endothelium in some cancers. However, as research progressed, numerous experiments conclusively demonstrated that CD248 is a marker for stromal fibroblasts, is not selectively expressed on tumor endothelial cells, and is mainly expressed by tumor mesenchymal fibroblasts and pericytes subpopulations associated with tumor vasculature, but not by tumor endothelial cells[26, 43-46]. Also, this result is consistent with our functional and pathway enrichment results. KA Khan et al. found that CD248 binds to a separate region of MMRN2 derived from CLEC14A and CD93, and that a recombinant peptide of MMRN2 spanning the binding region of CLEC14A and CD93 blocks the binding of the extracellular structural domain of CLEC14A to the surface of endothelial cells in anti-angiogenic effect in vitro and reduced tumor growth in a mouse model[44]. These findings identify novel protein interactions involving CLEC14A, CD93 and CD248 that could serve as targeting components for angiogenesis. The relevance of MMRN2 in angiogenesis has been demonstrated, however, interestingly, the studies by $E$ Lorenzon et al. and by Roberta Colladel et al. describe it as a vasopressor molecule that acts by isolating VEGF-A[47, 48]. The studies by KA Khan et al. and Zanivan et al. describe MMRN2 as a pro-angiogenic molecule that binds to cell surface proteins[44, 49]. This may be because MMRN2 interacts with CLEC14A, CD93 and CD248 separately from its interaction with VEGF-A. The study by Sven Christian et al. in 2008 suggests that CD248 is a marker of activated mesenchymal cells that form the human tumor mesenchyme, potentially affecting tumor migration and proliferation[26]. All in all, a large number of studies have shown that CD248 is weakly expressed in normal human tissues and strongly expressed in tumor tissues and that upregulation of CD248 is associated with tumor angiogenesis[26, 43-46, 50]. In conclusion, a large amount of evidence suggests that CD248 gene has a greater potential and value in tumor anti-angiogenic therapy and deserves further exploration.

Meanwhile, tumor development, progression and metastasis are highly dependent on the tumor mesenchyme, which consists of neointima, activated fibroblasts, infiltrative inflammatory cells and extracellular matrix[43]. In recent years, tumor anti-angiogenic therapy has also been an active area of research in tumor therapy. According to research findings, like normal tissues, tumor tissues also need blood to maintain their nutrient supply and oxygen supply, and inhibiting tumor angiogenesis can effectively prevent and treat tumors or delay tumor progression and metastasis[51-59]. In normal tissues, the dynamic balance between pro- and anti-angiogenic factors is relied on to maintain the morphology and function of normal blood vessels. However, in tumor tissues, the initiation of angiogenesis is induced when pro-angiogenic signals dominate due to the continuous unbalanced expression of pro- and anti-angiogenic factors, a process known as the " angiogenic switch"[60, 61]. Subsequently, this leads to the formation and functioning of tumor vessels and the resulting tumor vessels that are morphologically and functionally distinct from normal vessels. Currently, angiogenesis inhibitors exert their effects on tumor vasculature through three possible mechanisms, namely vascular depletion, vascular normalization and immune activation[62]. Although tumor anti-angiogenic therapy is currently a hot topic of research, further therapeutic improvements are hampered by, the lack of reliable 
biomarkers with predictive characteristics for anti-angiogenic therapy[56]. Thus, tumor angiogenesisrelated markers are currently of great value and the potential of CD248 is further demonstrated.

Furthermore, with clinical trials, CD248 is actively being used as a cancer target. In 2014 Luis A et al. designed the first drug developed for the treatment of a wide range of advanced solid tumors[63]. In their study, the humanized monoclonal antibody MORAb-004 is designed to target endothelin, which is targeted from an immunotherapeutic perspective against endothelin requiring (to clarify, endothelin is an alias for CD248, but in this study endothelin was a protein different from our study), but the drug lacking the specificity and clinical benefit for the treatment of pancreatic cancer is not yet satisfactory. After study and analysis, we obtained three gene axes, AC008040.1-hsa-miR-200c-3p-CD248 axis, AC055822.1hsa-miR-200c-3p-CD248 axis, and RRN3P2-hsa-miR-200c-3p-CD248 axis, which can be used as promising diagnostic biomarkers and therapeutic targets for pancreatic cancer. The three gene axes, RRN3P2-hsa-miR-200c-3p-CD248, could be promising diagnostic biomarkers and therapeutic targets for pancreatic cancer. By upregulating miRNA or downregulating IncRNA, it is possible to block the translation of mRNA (CD248) to produce proteins and thus regulate tumor angiogenesis. The result may be the inability to form new blood vessels due to the lack of basement membrane, and even if new vessels are formed, they are highly susceptible to disintegration and phagocytosis, resulting in dormant or even dead tumors without vascular supply.

When it comes to the extremely high mortality rate of pancreatic cancer and the lack of clinical treatments, it is urgent to study the mechanisms of pancreatic cancer development, progression and metastasis and effective treatment options. Based on the basic gene molecular mechanism of cancer and bioinformatics analysis, we obtained three IncRNA-miRNA-gene network axes provide promising diagnostic biomarkers for pancreatic cancer as anti-angiogenic therapeutic molecular targets and is expected to improve the prognosis of pancreatic cancer. By targeting and regulating the IncRNA-miRNAgene axis specific to CD248 gene in pancreatic cancer, therapeutic options for pancreatic cancer can be targeted and clinical benefits can be obtained. However, further studies and experiments are needed to validate these findings. Due to the complexity and highly uncontrollable nature of the tumor microenvironment, therapeutic approaches regarding targeting the tumor microenvironment should prioritize integrated or convergent targets rather than depleting specific targets, and inhibition of CD248 upregulation alone may not stop tumor angiogenesis and keep tumors in a dormant stage[56, 61, 64]. Hence, in further studies of CD248, a deeper understanding will require reflection on its cooperation with other molecules under specific microenvironmental conditions and multidrug approaches targeting various factors may be more successful in inhibiting cancer growth than monotherapies.

\section{Conclusions}

In short, our study established three new IncRNA-miRNA-gene network axes (AC008040.1-hsa-miR-200c3p-CD248 axis, AC055822.1-hsa-miR-200c-3p-CD248 axis, RRN3P2-hsa-miR-200c-3p-CD248 axis), which may help in clinical decision making for targeted molecular therapies. 


\section{Abbreviations}

PDCA: pancreatic carcinoma or pancreatic cancer; mRNA: coding RNA or messenger RNA; tRNA: transfer RNA; ncRNA: non-coding RNA; IncRNA: long non-coding RNA; miRNA: microRNA; TCGA: The Cancer Genome Atlas; Polll: RNA polmyerasell; Cl: confidence interval; GO: Gene Ontology; KEGG: Kyoto Encyclopedia of Genes and Genomes; BP: biological process; MF: molecular function; CC: celluar component; RT-PCR: Reverse Transcription-Polymerase Chain Reaction; KM: Kaplan-Meier

\section{Declarations}

\section{Acknowledgements}

Not applicable.

\section{Authors' contributions}

ZH drafted the manuscript and counted and plotted the diagram and tables. ZD and JZ researched the literature and participate in writing. DT and DW critically revised the article for important intellectual content. All authors read and approved the final manuscript.

\section{Funding}

This work is supported by grants from the Training Project of Key Talents of Youth Medicine in Jiangsu province, China [No. QNRC2016330] and High-level talent "six one project" top talent scientific project of jiangsu Province [No. LGY2019034].

\section{Availability of data and materials}

Not applicable.

\section{Ethics approval and consent to participate}

Not applicable.

\section{Consent for publication}

Not applicable.

\section{Competing interests}

The authors declare that they have no competing interests.

\section{References}

1. Siegel RL, Miller KD, Fuchs HE, Jemal A. Cancer Statistics, 2021. CA Cancer J Clin. 2021;71(1):7-33. 
2. Mizrahi JD, Surana R, Valle JW, Shroff RT. Pancreatic cancer. The Lancet. 2020;395(10242):200820.

3. Wolfgang CL, Herman JM, Laheru DA, Klein AP, Erdek MA, Fishman EK, Hruban RH. Recent progress in pancreatic cancer. CA Cancer J Clin. 2013;63(5):318-48.

4. Dvinge $H$, Guenthoer J, Porter PL, Bradley RK. : RNA components of the spliceosome regulate tissueand cancer-specific alternative splicing. Genome Res. 2019;29(10):1591-604.

5. Barbieri I, Kouzarides T. Role of RNA modifications in cancer. Nat Rev Cancer. 2020;20(6):303-22.

6. Chen S, Huang V, Xu X, Livingstone J, Soares F, Jeon J, Zeng Y, Hua JT, Petricca J, Guo H, et al. Widespread and Functional RNA Circularization in Localized Prostate Cancer. Cell. 2019;176(4):83143 e822.

7. Delaunay S, Frye M. RNA modifications regulating cell fate in cancer. Nat Cell Biol. 2019;21(5):5529.

8. Dvinge H, Kim E, Abdel-Wahab O, Bradley RK. RNA splicing factors as oncoproteins and tumour suppressors. Nat Rev Cancer. 2016;16(7):413-30.

9. Goodall GJ, Wickramasinghe VO. RNA in cancer. Nat Rev Cancer. 2021;21(1):22-36.

10. Graubert TA, Shen D, Ding L, Okeyo-Owuor T, Lunn CL, Shao J, Krysiak K, Harris CC, Koboldt DC, Larson DE, et al. Recurrent mutations in the U2AF1 splicing factor in myelodysplastic syndromes. Nat Genet. 2011;44(1):53-7.

11. Gruber AJ, Zavolan M. Alternative cleavage and polyadenylation in health and disease. Nat Rev Genet. 2019;20(10):599-614.

12. Jiang Q, Crews LA, Holm F, Jamieson CHM. RNA editing-dependent epitranscriptome diversity in cancer stem cells. Nat Rev Cancer. 2017;17(6):381-92.

13. Lee SH, Singh I, Tisdale S, Abdel-Wahab O, Leslie CS, Mayr C. Widespread intronic polyadenylation inactivates tumour suppressor genes in leukaemia. Nature. 2018;561(7721):127-31.

14. Masamha CP, Xia Z, Yang J, Albrecht TR, Li M, Shyu AB, Li W, Wagner EJ. CFIm25 links alternative polyadenylation to glioblastoma tumour suppression. Nature. 2014;510(7505):412-6.

15. Obeng EA, Stewart C, Abdel-Wahab O. Altered RNA Processing in Cancer Pathogenesis and Therapy. Cancer Discov. 2019;9(11):1493-510.

16. Quesada V, Conde L, Villamor N, Ordonez GR, Jares P, Bassaganyas L, Ramsay AJ, Bea S, Pinyol M, Martinez-Trillos $\mathrm{A}$, et al. Exome sequencing identifies recurrent mutations of the splicing factor SF3B1 gene in chronic lymphocytic leukemia. Nat Genet. 2011;44(1):47-52.

17. Vo JN, Cieslik M, Zhang Y, Shukla S, Xiao L, Zhang Y, Wu YM, Dhanasekaran SM, Engelke CG, Cao X, et al. The Landscape of Circular RNA in Cancer. Cell. 2019;176(4):869-81 e813.

18. Wang E, Lu SX, Pastore A, Chen X, Imig J, Chun-Wei Lee S, Hockemeyer K, Ghebrechristos YE, Yoshimi A, Inoue D, et al. Targeting an RNA-Binding Protein Network in Acute Myeloid Leukemia. Cancer Cell. 2019;35(3):369-84 e367. 
19. Yoshida K, Sanada M, Shiraishi Y, Nowak D, Nagata Y, Yamamoto R, Sato Y, Sato-Otsubo A, Kon A, Nagasaki $\mathrm{M}$, et al. Frequent pathway mutations of splicing machinery in myelodysplasia. Nature. 2011;478(7367):64-9.

20. Anastasiadou E, Jacob LS, Slack FJ. Non-coding RNA networks in cancer. Nat Rev Cancer. 2018;18(1):5-18.

\section{1. <MicroRNAs and Their Regulatory Roles in Plant-Environment Interactions..pdf>.}

22. Eichhorn SW, Guo H, McGeary SE, Rodriguez-Mias RA, Shin C, Baek D, Hsu SH, Ghoshal K, Villen J, Bartel DP. mRNA destabilization is the dominant effect of mammalian microRNAs by the time substantial repression ensues. Mol Cell. 2014;56(1):104-15.

23. Gebert LFR, MacRae IJ. Regulation of microRNA function in animals. Nat Rev Mol Cell Biol. 2019;20(1):21-37.

24. Xie D, Chen M, Niu J, Wang L, Li Y, Fang X, Li P, Qi Y. Phase separation of SERRATE drives dicing body assembly and promotes miRNA processing in Arabidopsis. Nat Cell Biol. 2021;23(1):32-9.

25. Christian S, Ahorn H, Koehler A, Eisenhaber F, Rodi HP, Garin-Chesa P, Park JE, Rettig WJ, Lenter MC. Molecular cloning and characterization of endosialin, a C-type lectin-like cell surface receptor of tumor endothelium. J Biol Chem. 2001;276(10):7408-14.

26. Christian S, Winkler R, Helfrich I, Boos AM, Besemfelder E, Schadendorf D, Augustin HG. Endosialin (Tem1) is a marker of tumor-associated myofibroblasts and tumor vessel-associated mural cells. Am J Pathol. 2008;172(2):486-94.

27. Fiorini N, Leaman R, Lipman DJ, Lu Z. How user intelligence is improving PubMed. Nat Biotechnol 2018.

28. Yuan H, Yan M, Zhang G, Liu W, Deng C, Liao G, Xu L, Luo T, Yan H, Long Z, et al. CancerSEA: a cancer single-cell state atlas. Nucleic acids research. 2019;47(D1):D900-8.

29. Safran M, Dalah I, Alexander J, Rosen N, Iny Stein T, Shmoish M, Nativ N, Bahir I, Doniger T, Krug H, et al: GeneCards Version 3: the human gene integrator. Database (Oxford) 2010, 2010:baq020.

30. Rebhan M, Chalifa-Caspi V, Prilusky J, Lancet D. GeneCards: integrating information about genes, proteins and diseases. Trends Genet. 1997;13(4):163.

31. UniProt C. UniProt: the universal protein knowledgebase in 2021. Nucleic acids research. 2021;49(D1):D480-9.

32. Amberger JS, Bocchini CA, Scott AF, Hamosh A. OMIM.org: leveraging knowledge across phenotypegene relationships. Nucleic acids research. 2019;47(D1):D1038-43.

33. Gao J, Aksoy BA, Dogrusoz U, Dresdner G, Gross B, Sumer SO, Sun Y, Jacobsen A, Sinha R, Larsson E, et al. Integrative analysis of complex cancer genomics and clinical profiles using the cBioPortal. Sci Signal. 2013;6(269):pl1.

34. Zhou G, Soufan O, Ewald J, Hancock REW, Basu N, Xia J: NetworkAnalyst 3.0: a visual analytics platform for comprehensive gene expression profiling and meta-analysis. Nucleic acids research 2019, 47(W1):W234-W241. 
35. Xia J, Lyle NH, Mayer ML, Pena OM, Hancock RE. INVEX-a web-based tool for integrative visualization of expression data. Bioinformatics. 2013;29(24):3232-4.

36. Xia J, Benner MJ, Hancock RE. NetworkAnalyst-integrative approaches for protein-protein interaction network analysis and visual exploration. Nucleic acids research 2014, 42(Web Server issue):W167-174.

37. Xia J, Fjell CD, Mayer ML, Pena OM, Wishart DS, Hancock RE. INMEX-a web-based tool for integrative meta-analysis of expression data. Nucleic acids research. 2013;41:W63-70. (Web Server issue).

38. Szklarczyk D, Gable AL, Lyon D, Junge A, Wyder S, Huerta-Cepas J, Simonovic M, Doncheva NT, Morris JH, Bork P, et al. STRING v11: protein-protein association networks with increased coverage, supporting functional discovery in genome-wide experimental datasets. Nucleic acids research. 2019;47(D1):D607-13.

39. Szklarczyk D, Morris JH, Cook H, Kuhn M, Wyder S, Simonovic M, Santos A, Doncheva NT, Roth A, Bork P, et al. The STRING database in 2017: quality-controlled protein-protein association networks, made broadly accessible. Nucleic acids research. 2017;45(D1):D362-8.

40. Otasek D, Morris JH, Boucas J, Pico AR, Demchak B. Cytoscape Automation: empowering workflowbased network analysis. Genome Biol. 2019;20(1):185.

41. Li JH, Liu S, Zhou H, Qu LH, Yang JH. starBase v2.0: decoding miRNA-ceRNA, miRNA-ncRNA and protein-RNA interaction networks from large-scale CLIP-Seq data. Nucleic acids research. 2014;42(Database issue):D92-7.

42. St Croix B, Rago C, Velculescu V, Traverso G, Romans KE, Montgomery E, Lal A, Riggins GJ, Lengauer C, Vogelstein B, Kinzler KW. Genes Expressed in Human Tumor Endothelium. Science. 2000;289(5482):1197-202.

43. Becker R, Lenter MC, Vollkommer T, Boos AM, Pfaff D, Augustin HG, Christian S. Tumor stroma marker endosialin (Tem1) is a binding partner of metastasis-related protein Mac-2 BP/90K. FASEB J. 2008;22(8):3059-67.

44. Khan KA, Naylor AJ, Khan A, Noy PJ, Mambretti M, Lodhia P, Athwal J, Korzystka A, Buckley CD, Willcox BE, et al. Multimerin-2 is a ligand for group 14 family C-type lectins CLEC14A, CD93 and CD248 spanning the endothelial pericyte interface. Oncogene. 2017;36(44):6097-108.

45. Kontsekova S, Polcicova K, Takacova M, Pastorekova S. Endosialin: molecular and functional links to tumor angiogenesis. Neoplasma. 2016;63(2):183-92.

46. Simonavicius N, Robertson D, Bax DA, Jones C, Huijbers IJ, Isacke CM. Endosialin (CD248) is a marker of tumor-associated pericytes in high-grade glioma. Mod Pathol. 2008;21(3):308-15.

47. Lorenzon E, Colladel R, Andreuzzi E, Marastoni S, Todaro F, Schiappacassi M, Ligresti G, Colombatti A, Mongiat M. MULTIMERIN2 impairs tumor angiogenesis and growth by interfering with VEGFA/VEGFR2 pathway. Oncogene. 2012;31(26):3136-47.

48. Sandler A, Gray R, Perry MC, Brahmer J, Schiller JH, Dowlati A, Lilenbaum R, Johnson DH. Paclitaxelcarboplatin alone or with bevacizumab for non-small-cell lung cancer. N Engl J Med. 
2006;355(24):2542-50.

49. Zanivan S, Maione F, Hein MY, Hernandez-Fernaud JR, Ostasiewicz P, Giraudo E, Mann M. SILACbased proteomics of human primary endothelial cell morphogenesis unveils tumor angiogenic markers. Mol Cell Proteomics. 2013;12(12):3599-611.

50. Bagley RG, Rouleau C, St Martin T, Boutin P, Weber W, Ruzek M, Honma N, Nacht M, Shankara S, Kataoka $S$, et al. Human endothelial precursor cells express tumor endothelial marker 1/endosialin/CD248. Mol Cancer Ther. 2008;7(8):2536-46.

51. Albini A, Tosetti F, Li VW, Noonan DM, Li WW. Cancer prevention by targeting angiogenesis. Nat Rev Clin Oncol. 2012;9(9):498-509.

52. Casazza A, Laoui D, Wenes M, Rizzolio S, Bassani N, Mambretti M, Deschoemaeker S, Van Ginderachter JA, Tamagnone L, Mazzone M. Impeding macrophage entry into hypoxic tumor areas by Sema3A/Nrp1 signaling blockade inhibits angiogenesis and restores antitumor immunity. Cancer Cell. 2013;24(6):695-709.

53. Aggarwal R, Thomas S, Pawlowska N, Bartelink I, Grabowsky J, Jahan T, Cripps A, Harb A, Leng J, Reinert A, et al. Inhibiting Histone Deacetylase as a Means to Reverse Resistance to Angiogenesis Inhibitors: Phase I Study of Abexinostat Plus Pazopanib in Advanced Solid Tumor Malignancies. J Clin Oncol. 2017;35(11):1231-9.

54. Kangsamaksin T, Murtomaki A, Kofler NM, Cuervo H, Chaudhri RA, Tattersall IW, Rosenstiel PE, Shawber CJ, Kitajewski J. NOTCH decoys that selectively block DLL/NOTCH or JAG/NOTCH disrupt angiogenesis by unique mechanisms to inhibit tumor growth. Cancer Discov. 2015;5(2):182-97.

55. Sandler A, Gray R, Perry MC, Brahmer J, Schiller JH, Dowlati A, Lilenbaum R, Johnson DH. Paclitaxelcarboplatin alone or with bevacizumab for non-small-cell lung cancer. N Engl J Med. 2006;355(24):2542-50.

56. Daum S, Hagen H, Naismith E, Wolf D, Pircher A. The Role of Anti-angiogenesis in the Treatment Landscape of Non-small Cell Lung Cancer - New Combinational Approaches and Strategies of Neovessel Inhibition. Front Cell Dev Biol. 2020;8:610903.

57. Gridelli C, de Castro Carpeno J, Dingemans AC, Griesinger F, Grossi F, Langer C, Ohe Y, Syrigos K, Thatcher N, Das-Gupta A, et al. Safety and Efficacy of Bevacizumab Plus Standard-of-Care Treatment Beyond Disease Progression in Patients With Advanced Non-Small Cell Lung Cancer: The AvaALL Randomized Clinical Trial. JAMA Oncol. 2018;4(12):e183486.

58. Teleanu RI, Chircov C, Grumezescu AM, Teleanu DM. Tumor Angiogenesis and Anti-Angiogenic Strategies for Cancer Treatment. Journal of clinical medicine 2019, 9(1).

59. Kim C, Yang H, Fukushima Y, Saw PE, Lee J, Park JS, Park I, Jung J, Kataoka H, Lee D, et al. Vascular RhoJ is an effective and selective target for tumor angiogenesis and vascular disruption. Cancer Cell. 2014;25(1):102-17.

60. Hanahan D, Folkman J. Patterns and emerging mechanisms of the angiogenic switch during tumorigenesis. Cell. 1996;86(3):353-. 
61. Bergers G, Benjamin LE. Tumorigenesis and the angiogenic switch. Nat Rev Cancer. 2003;3(6):40110.

62. Lugano R, Ramachandran M, Dimberg A. Tumor angiogenesis: causes, consequences, challenges and opportunities. Cell Mol Life Sci. 2020;77(9):1745-70.

63. Diaz LA Jr, Coughlin CM, Weil SC, Fishel J, Gounder MM, Lawrence S, Azad N, O'Shannessy DJ, Grasso L, Wustner J, et al. A first-in-human phase I study of MORAb-004, a monoclonal antibody to endosialin in patients with advanced solid tumors. Clin Cancer Res. 2015;21(6):1281-8.

64. Ho WJ, Jaffee EM, Zheng L. The tumour microenvironment in pancreatic cancer - clinical challenges and opportunities. Nat Rev Clin Oncol. 2020;17(9):527-40.

\section{Figures}

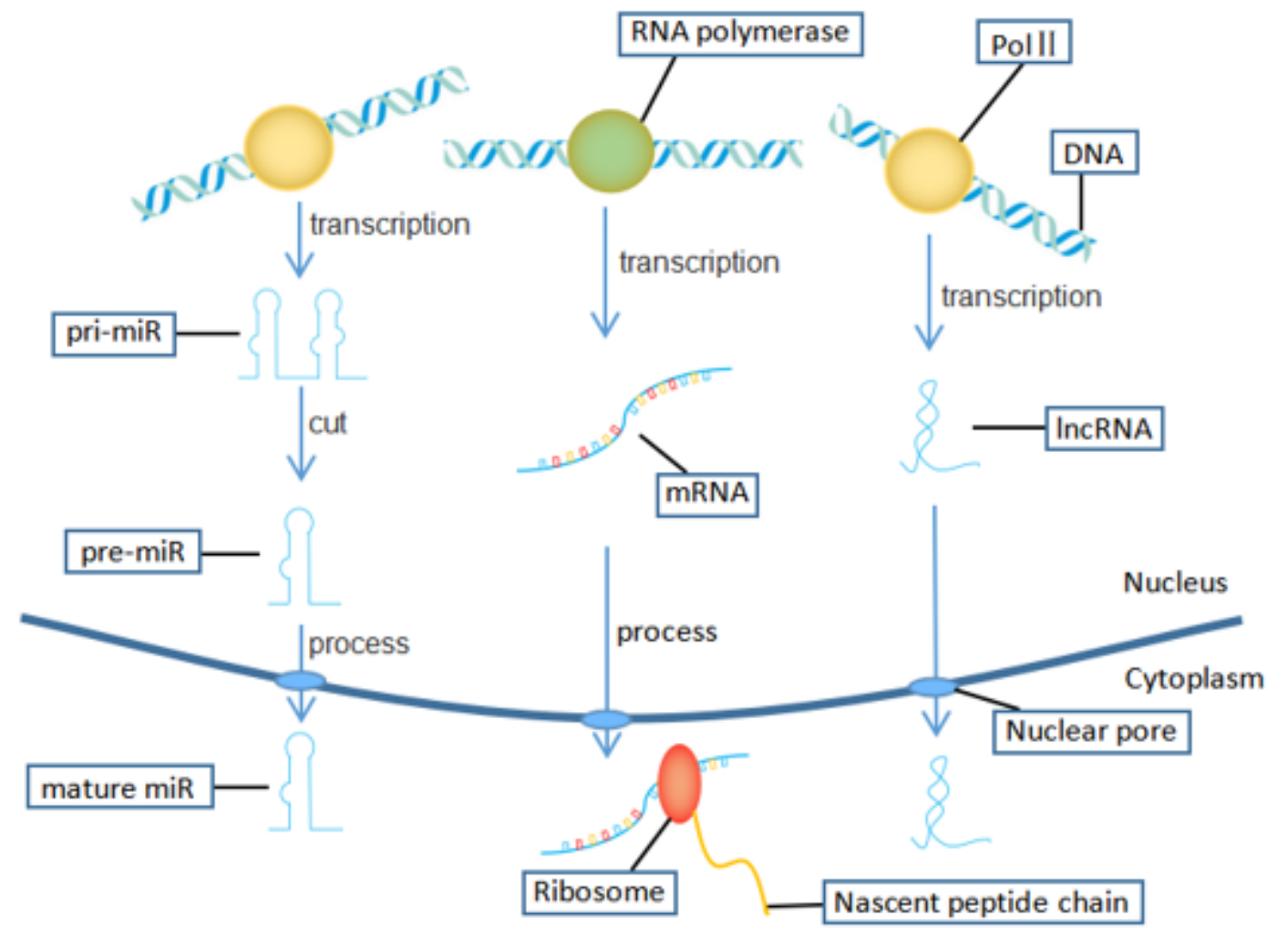

\section{Figure 1}

Formation of mRNA, IncRNA, miRNA: 1. mRNA囚after transcription of genes by RNA polymerase, introns are removed from precursor mRNA by spliceosomes, and mRNA is further processed into mature transcripts, which are then exported from the nucleus to the cytoplasm and translated into proteins by ribosomes. 2. miRNA: some miRNAs are transcribed from protein-coding genes' introns, while others are transcribed by RNA polmyerasell (PolII) to produce pri-miR from their own dedicated transcripts. In the 
nucleus, the pri-miR is cut to liberate the pre-miR hairpin by endoribonuclease. The pre-miR is then exported from the nucleus and the loop of the pre-miR is cut by the endoribonuclease cleaves to produce the mature miRNA in the cytoplasm. 3.IncRNA: long non-coding RNAs (IncRNAs) are RNAs that are more than 200 nucleotides in length and do not encode proteins (although some small peptides encoded by IncRNAs have been detected). After transcription by Polll they can function in both the nucleus and cytoplasm.

a

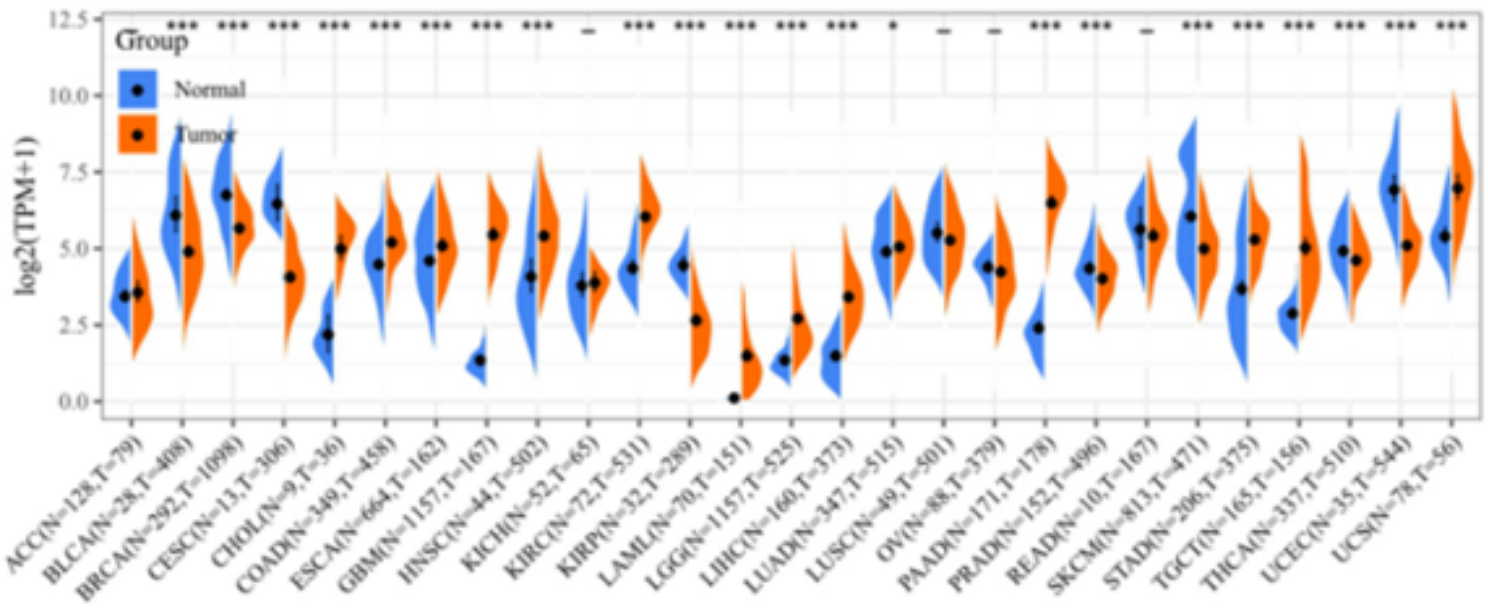

b

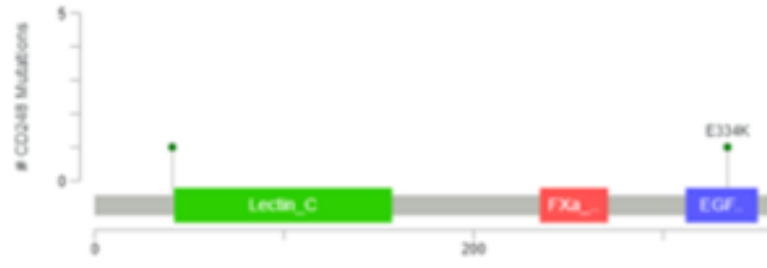

c

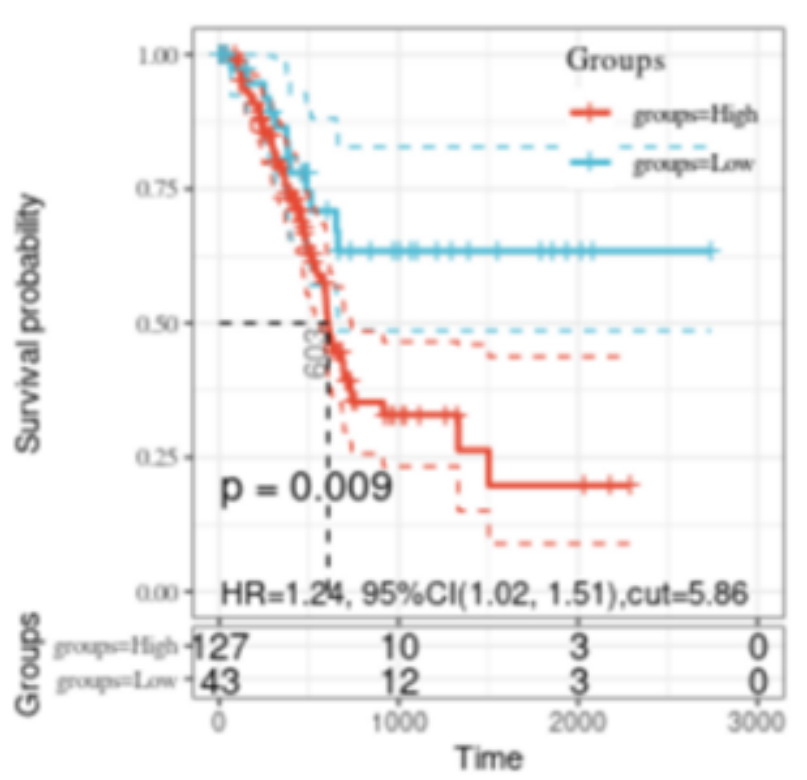

d

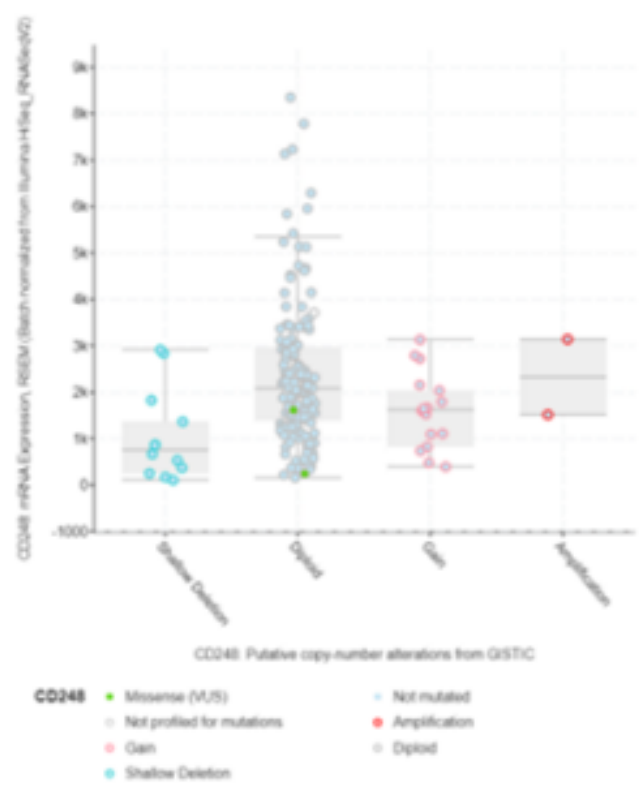

Figure 2 
A summary of CD248 expression differences in 27 normal and cancer tissues in tissues. The databases used were TCGA and GTEx. The test used for the analysis was the t-test. Among them, it was downregulated in BLCA, BRCA, CESC, KIRP, PRAD, SKCM, THCA and UCEC. Up-regulated in CHOL, COAD,

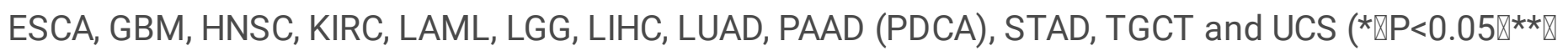
$p<0.01 \rrbracket \star \star \star \star p<0.001)$. b Alterations of CD248 in PDCA. The OncoPrint provides an overview of genomic alterations in CD248 affecting individual samples in PDCA from the TCGA. The different types of genetic alterations are highlighted in different colors. c KM curve: CD248 upregulation predicts poor prognosis in PDCA. $d$ The transcription of CD248 in 176 patients. The result shows that copy-number alterations include amplification, gain, diploid and shallow deletion, and diploid expression was the most abundant.

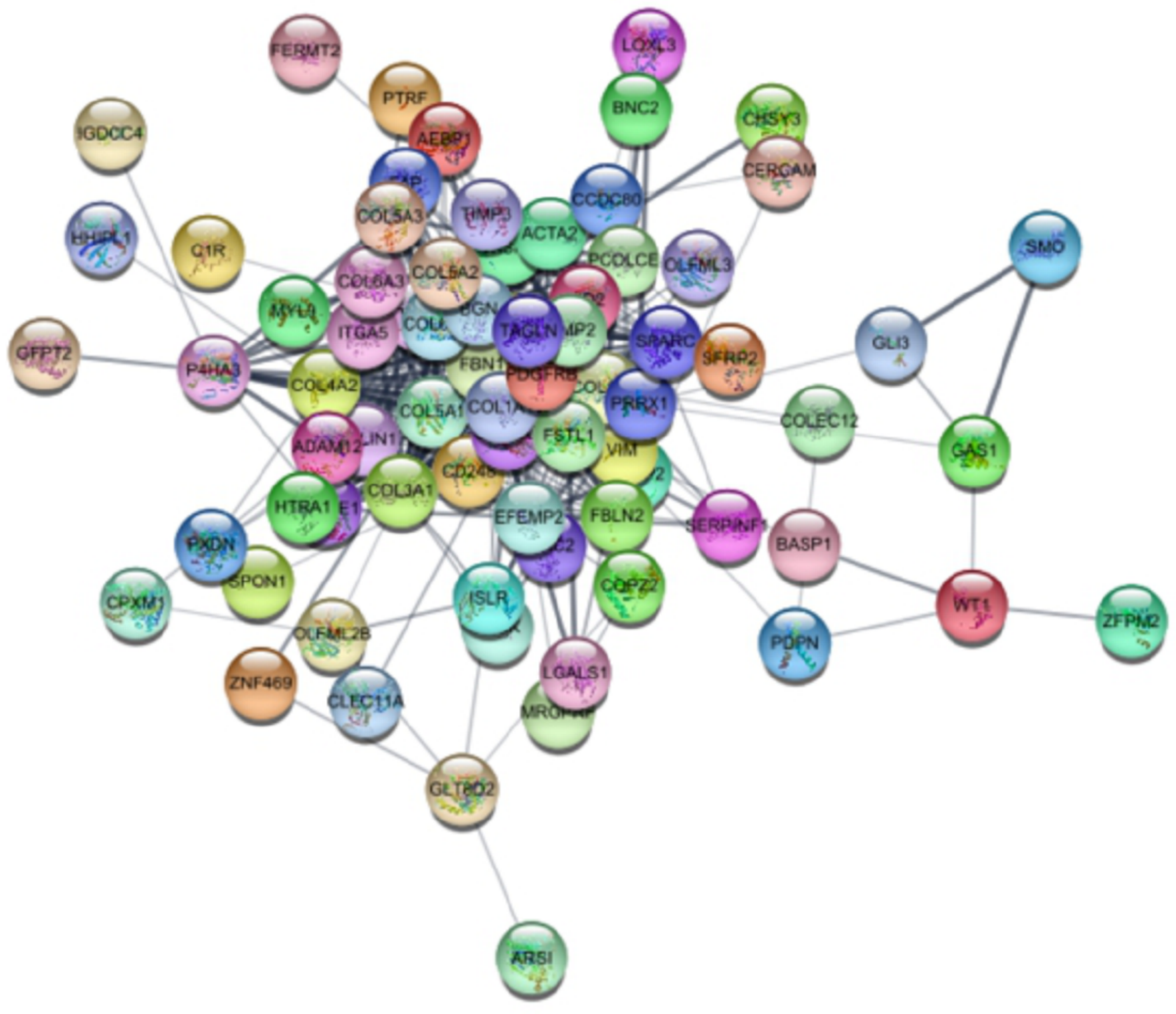

\section{Figure 3}

Map of 104 genes directly or indirectly associated with CD248 in protein-protein interactions (from Cytoscape). 
a

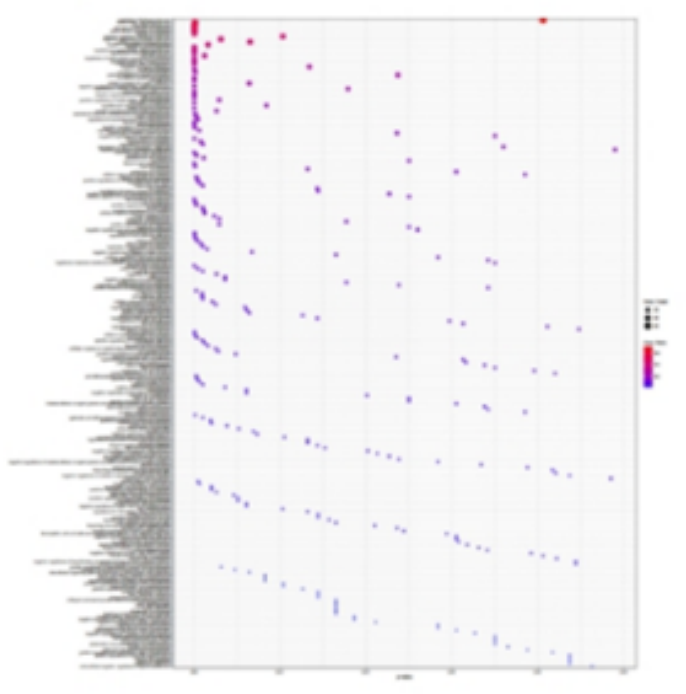

c

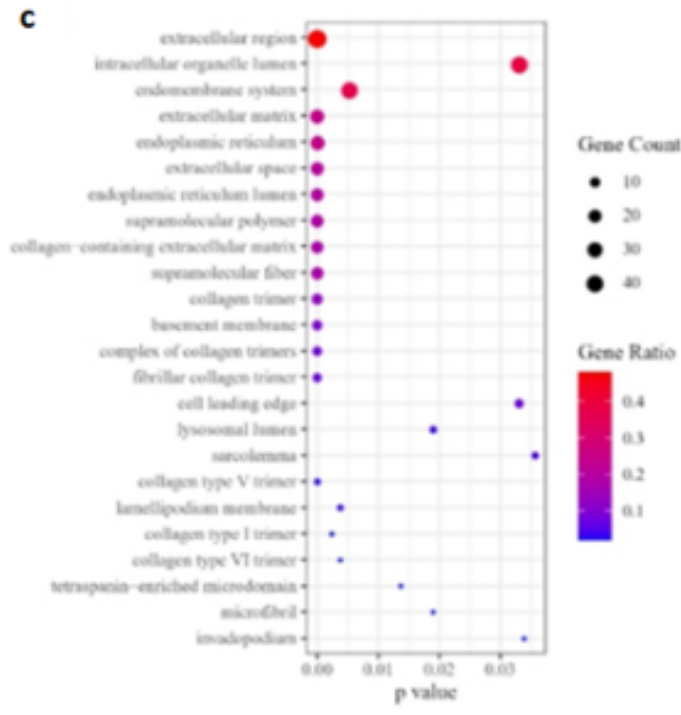

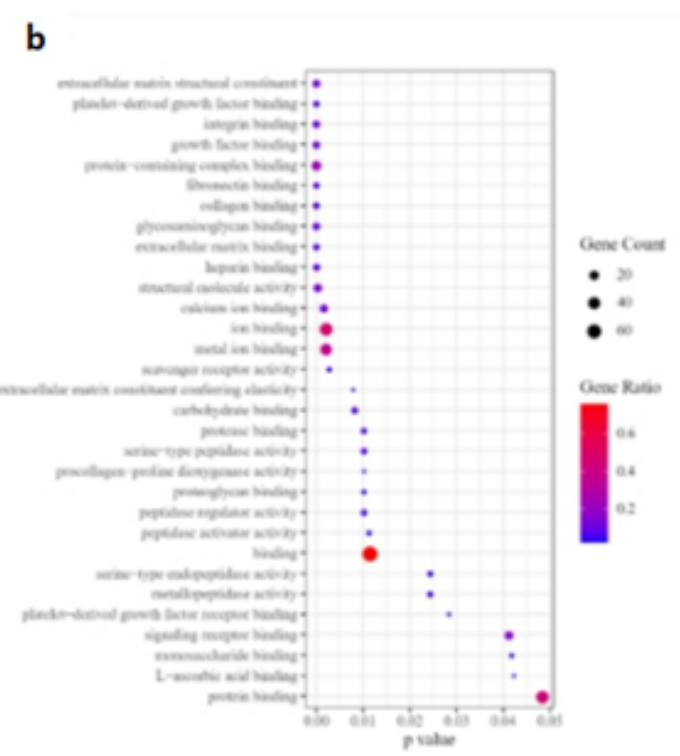

d

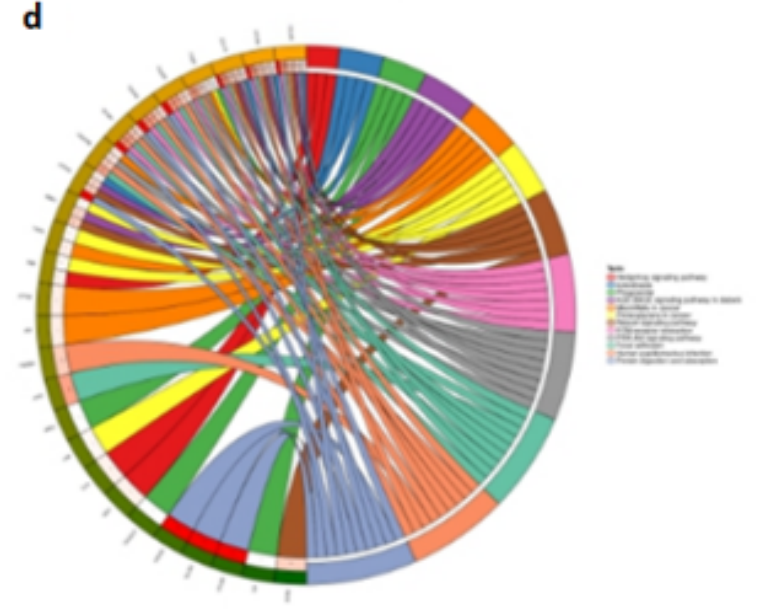

\section{Figure 4}

Gene ontology and KEGG pathway enrichment. a biological process (BP). b molecular function (MF). c cellular component (CC). d KEGG includes Protein digestion and absorption, focal adhesion, human papillomavirus infection, PI3K-Akt signaling pathway, ECM-receptor interaction, relaxin signaling pathway, AGE-RAGE signaling pathway in diabetic complications, microRNAs in cancer, proteoglycans in cancer, amoebiasis, phagosome, hedgehog signaling pathway. 
a

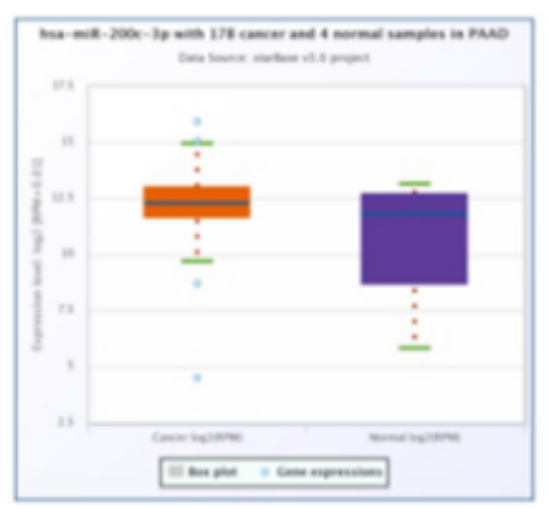

d

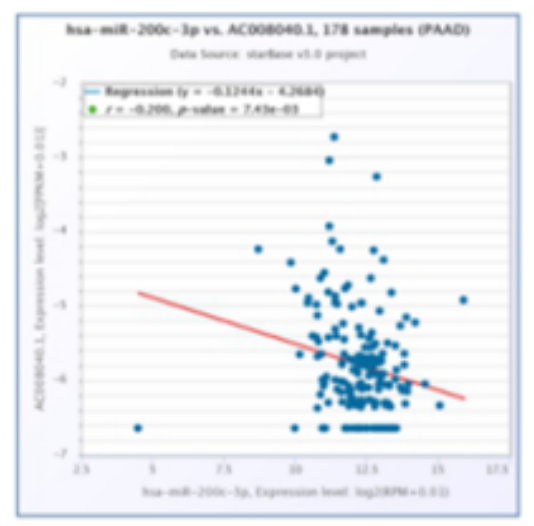

g

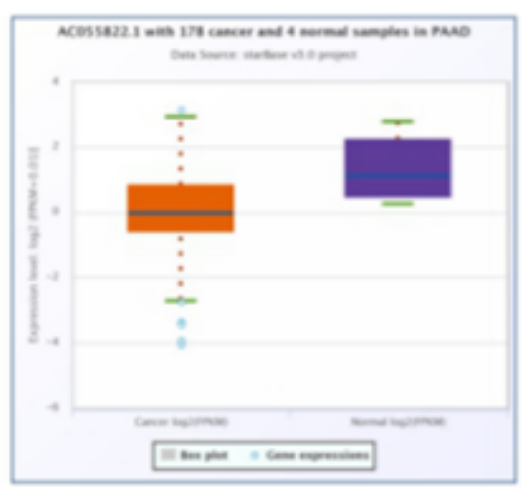

b

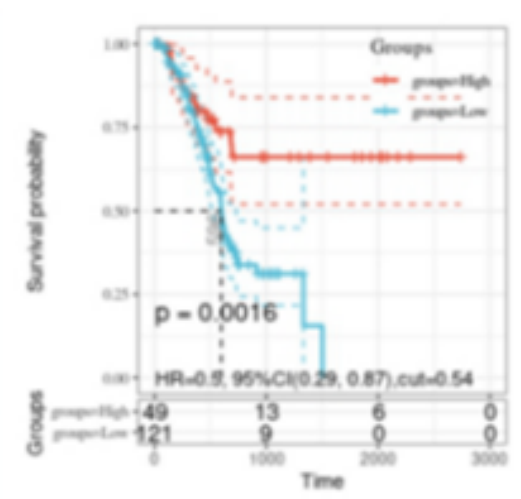

e

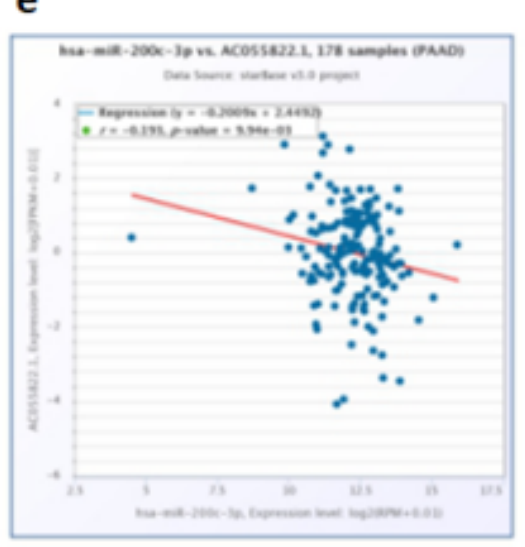

h

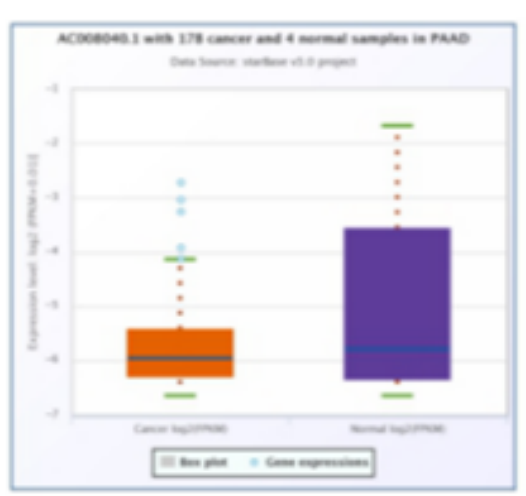

c

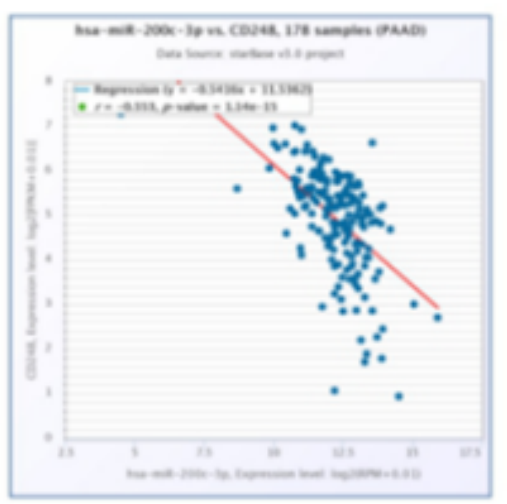

f

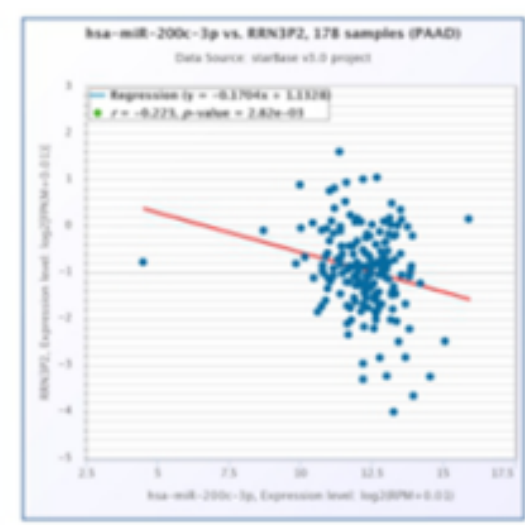

i

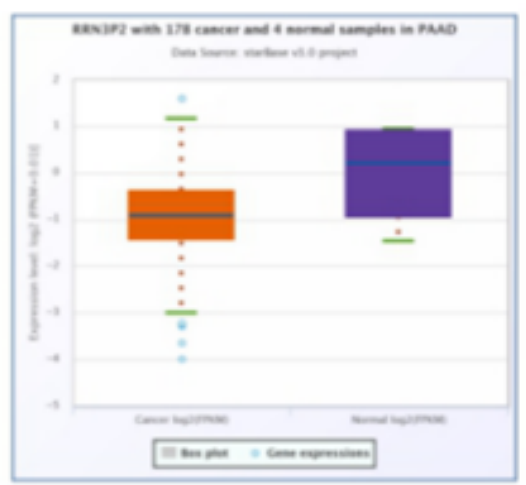

\section{Figure 5}

a Difference of hsa-miR-200c-3p in expression in PDCA tissues and normal tissues $(p=0.012)$. b KM curve of hsa-miR-200c-3p in PDCA. The upregulation of hsa-miR-200c-3p predictes a poor prognosis of PDCA. c Co-expression of hsa-miR-200c-3p associated with CD248. d-f Co-expression of AC008040.1, AC055822.1 and RRN3P2 associated with hsa-miR-200c-3p. g-i Difference of AC008040.1 ( $p=0.038)$, AC055822.1 $(p=0.031)$ and RRN3P2 $(p=0.042)$ in expression in PDCA tissues and normal tissues. 